\title{
CONTROL DEL DOMINIO ÚTIL Y SALVAGUARDA DEL DIRECTO EN LA ENFITEUSIS SEÑORIAL VALENCIANA: LOS CABREVES
}

\author{
POR
}

\author{
ANTONIO GIL OLCINA
}

La enfiteusis, habitual en los señoríos valencianos, consistía en un censo con dominio que facultaba al estabiliente y sucesores para cobrar canon, exigir cabreve, percibir laudemio, ejercitar la fadiga y, en su caso, el comiso. Así pues, venía a coincidir con la modalidad de censo que, según Belluga, supone cargar a una propiedad con laudemio, fadiga y cualquier otro derecho enfitéutico. ${ }^{1}$ Una visión sumamente interesante del contrato enfitéutico es la que proporciona, a mediados del siglo xviII, el gobernador del marquesado de Lombay, Francisco Benlloch, quien, al hilo de su discurso, hace una serie de reflexiones de evidente oportunidad para introducir la cuestión que nos ocupa.

Dice Benlloch que el contrato enfitéutico «es una consignación de tierras, ó casas, o un establecimiento á alguna persona, para que pueda cultivar, labrar y descubrir las tierras, con reserva de la solariega propiedad directa, y del Dominio mayor, con la condición de partir con el dueño los frutos, y satisfacer annual censo, en reconocimiento de el dicho Dominio mayor, de modo que el vasallo emphiteuta solo tiene sobre la casa consignada el dominio útil para percivir los frutos, un punto más que usufructo, por quanto es trascendental útil dominio á

${ }^{1}$ Belluga, P.: Speculum principium ac iustitiae. París, 1530, f. 179-180. Peset, M.: «L'emfiteusi al Regne de València. Una anàlisi jurídica», Estudis d'Historia Agraria, 1983, 7, p. 101.

Antonio Gil Olcina: Instituto Universitario de Geografía en la Universidad de Alicante. 
los herederos emphiteutas, como cumplan los colonos vasallos con el canon, vectigál, ó annuas pensiones, y ordinaria particion [...] se advierte que los colonos, emphiteutas, no tienen facultad de enagenar la cosa establecida con aquella potestad que transfiera un absoluto dominio, ó que sea enagenacion de absoluto contrato real de verdadero Dueño, como es en la venta real, adjudicacion en pago de deuda, que transfiere ambos dominios; por lo que tienen precision estos vasallos en los contratos reales, á que se agrega la permuta de una cosa afecta al dominio por otra, de pedir licencia al señor directo solariego, para poder enagenar manifestando á quien, para que el señor directo no pierda el Derecho de tanteo, que momentaneo corre por nueve dias (sic) peremptorios según real disposicion de estos reinos, esto es quedarse dicho señor con la tierra por el tanto en que se vende la cosa raiz, y consignarla a otro, ó para sí. Y tambien por si al señor no le tiene quenta el vasallo comprador [...] y es tan precisa esta dominical licencia, que sin ella se puede comisar la cosa raiz enagenada en pena de la inobediencia y rebeldía al dominio mayor, á quien la naturaleza del contrato enphiteuseo atribuye esta determinada accion legal.

Pero hoy en dia està tan relaxado este Principe Derecho, que por no causar á la vista los vendedores el Laudemio, que llaman Luismo, y que se debe al alodio de el excelso patrimonio, otorgan las escrituras de venta impermisas, que de serlas, se llegàra á saber el quanto de el Laudemio, ante escrivano forastero de esta jurisdiccion, cuyo remedio se puede poner en el cabreve, y cuyo abuso se puede cortar comisando. Pero la lastima que no lo executan assi los juezes, porque toleran indevidamente estos difugios, no pidiendo en el reconocimiento la justificacion de haberse pagado el Luismo, y por esso por el tiempo llegan á perderse las regalias, como las tierras á ser francas, por omision y gracias de los juezes de el cabreve, que á sus paniaguados, las dan por libres de tributo en perjuicio del vinculo de la cassa, y por esto no solo se distrahe el patrimonio, si que tambien por aquello se invierte el orden de este contrato; Y lo que sucede es, que por no ir con rigor, con justicia en ambos asumptos, se dá alas á los vasallos colonos, para que en lo succesivo se alegue tolerancia, y consentimientos, en que pueden fundar una costumbre que tenga vigor de Ley, que para rebatirla sea necesario un litigio». ${ }^{2}$

${ }^{2}$ Benlloch, F.: Marquesado de Llombay, 1756. Valencia, Suc. Vives Mora, 1975, pp. 114-118. 
Volveremos luego sobre algunas de las consideraciones de Benlloch. Pero no antes de subrayar que los establiments señoriales, emanados de cartas pueblas y concordias, exceden notoriamente el contenido de la mera enfiteusis alodial al incluir aspectos ajenos al contrato entre particulares, por cuanto el censualista, además de intervenir como dueño de casas y tierras, lo hace en su condición de titular de la jurisdicción o, en la fundación de lugares alfonsinos, de seguro candidato al logro de la misma. ${ }^{3}$ La acomodación de aquéllos al régimen señorial se evidencia en una serie de hechos y efectos, tales como mayor cuantía del laudemio, ejercicio unilateral de la fadiga, inclusión generalizada de regalías, acusada presencia de la pena de comiso y frecuente participación dominical, en mayor o menor porcentaje, de los diezmos.

Por su extraordinaria virtualidad para radicar al colono, asociar el dictado de vasallaje y facilitar la recaudación de regalías, la enfiteusis vino a constituir la médula, al tiempo que la jurisdicción era espinazo, de las cartas pueblas o concordias otorgadas en el antiguo reino de Valencia por titulares de señoríos seculares, eclesiásticos, abadengos y de órdenes militares, que, a finales del Antiguo Régimen, cubrían las tres cuartas partes del territorio entonces valenciano, y gravitaban sobre una mayoría de villas y lugares. En 1797, según el Censo de Godoy, ${ }^{4}$ las entidades y casas útiles del Reino-Provincia de Valencia ofrecían la adscripción que se muestra en el Cuadro de la página siguiente.

Mayor aun resultaba la preponderancia de los señoríos en superficie. A partir del Nomenclátor de Floridablanca ${ }^{5}$ y de la Relación de I. V. Franco,${ }^{6}$ hemos calculado, mediante verificación de límites y extensiones, que los señoríos citados por dichas fuentes totalizaban, vísperas de la incorporación de jurisdicciones, el 74,52\% del reino de Valencia, es decir, 15.955,09 kilómetros cuadrados, con la distribución que se muestra en el Cuadro de la página siguiente.

${ }^{3}$ Gil Olcina, A.: «La propiedad de la tierra en los señoríos de jurisdicción alfonsina», Investigaciones Geográficas, 1983,1, pp. 7-24.

${ }^{4}$ Censo de la población de España en el año 1797, executado de Orden del Rey en el de 1801. De Orden Superior en la Imprenta de Vega y Compañía, Madrid, XI y XXXIII.

5 España dividida en Provincias $e$ Intendencias y subdividida en partidos, corregimientos, alcaldías mayores, gobiernos políticos y militares así realengos como de órdenes, abadengo y señorio, Madrid, 1789, t. I, pp. 540-552.

${ }^{6}$ Franco, I.V.: Noticias de la actual población del Reyno de Valencia; la de sus despoblados desde la conquista por el rey D. Jaime Primero; las leguas que distan de la capital; los señoríos directos que la poseen; y las Diócesis a que pertenecen. Valencia, 1804.

$$
-203-
$$




\begin{tabular}{|c|c|c|c|c|c|}
\hline \multicolumn{6}{|c|}{$\begin{array}{l}\text { ADSCRIPCIÓN DE LAS ENTIDADES Y CASAS ÚTILES } \\
\text { DEL REINO-PROVINCIA DE VALENCIA EN } 1797 \\
\text { (Según el Censo de Godoy) }\end{array}$} \\
\hline & Ciudades & Villas & Lugares & Aldeas & Granjas \\
\hline 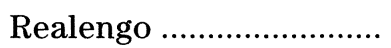 & 6 & 41 & 19 & 17 & 891 \\
\hline Abadengo ............................ & - & - & 13 & 1 & 3 \\
\hline Señorío eclesiástico ...... & - & 15 & 15 & 1 & 593 \\
\hline Señorío secular .............. & 3 & 103 & 271 & 12 & 70 \\
\hline De órdenes ........................ & - & 37 & 16 & 1 & 10 \\
\hline TOTAL ........................... & 9 & 196 & 334 & 32 & 1.567 \\
\hline
\end{tabular}

ADSCRIPCIÓN DE LAS ENTIDADES Y CASAS ÚTILES

DEL REINO-PROVINCIA DE VALENCIA EN 1797

(Según el Censo de Godoy). (Continuación)

\begin{tabular}{|c|c|c|c|}
\hline & Cotos reales & Despoblados & Casas útiles \\
\hline Realengo & 8 & 1 & 60.546 \\
\hline 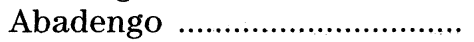 & 23 & - & 1.714 \\
\hline Señorío eclesiástico .............. & - & - & 6.842 \\
\hline Señorío secular ...................... & 16 & 21 & 83.849 \\
\hline 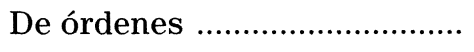 & 2 & - & 12.242 \\
\hline TOTAL & 49 & 22 & 165.193 \\
\hline
\end{tabular}

En suma, si se tiene en cuenta que faltan por contabilizar lugares alfonsinos que no alcanzaron o perdieron la condición de municipios, puede afirmarse, con escaso margen de error, que las tres cuartas partes del reino eran de señorío, con abrumador predominio del nobiliario.

Por supuesto, el elemento solariego quedaba, en superficie, a la zaga del jurisdiccional, ${ }^{7}$ y a más distancia todavía de éste aparecía el total de tierras establecidas, no sólo porque los yermos, en sus diversos tipos, ocupaban un espacio muy considerable, sino también debido a que en las tierras cultivadas había una distinción básica entre francas y pechadas, con el dato complementario de que una parte, aunque fuera minoritaria, de los predios pertenecientes a titulares de señoríos co-

7 Gil Olcina, A.: «Declive y ocaso de la enfiteusis señorial valenciana», Agricultura $y$ Sociedad, 1988, 49, pp. 289-299. 


\section{DISTRIBUCIÓN DE LOS SEÑORÍOS EN SUPERFICIE A PARTIR DEL NOMENCLÁTOR DE FLORIDABLANCA Y DE LA RELACIÓN DE I. V. FRANCO DEL REINO DE VALENCIA}

\begin{tabular}{|c|c|c|}
\hline & Extensión $\left(\mathrm{km}^{2}\right)$ & \% Reino de Valencia \\
\hline Realengo . & $5.455,92$ & 25,48 \\
\hline 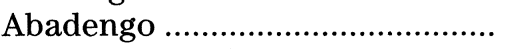 & 778,54 & 3,64 \\
\hline Señorío eclesiástico ..................... & 398,43 & 1,86 \\
\hline Señorío secular .......................... & $12.260,80$ & 57,26 \\
\hline 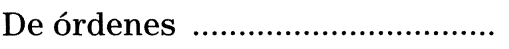 & $2.517,32$ & 11,76 \\
\hline TOTAL .... & $21.411,01$ & 100,00 \\
\hline
\end{tabular}

nocieron otras formas de tenencia, tales como arrendamiento a corto plazo, terraje, aparcería a medias y administración directa.

Implícitamente se acaba de afirmar que la enfiteusis fue la forma jurídica de explotación generalizada en el labrantío valenciano de titularidad señorial, a gran distancia de cualquier otra. Multitud de datos procedentes de cartas pueblas, concordias, cabreves, libros de enfiteutas, tablas de fadigas o giradoras, protocolos notariales, oficios y contadurías de hipotecas, primordialmente, y numerosos testimonios, entre ellos los muy valiosos de Cavanilles, ${ }^{8}$ confirman esta realidad.

Como se ha indicado, no cabe, en modo alguno, una identificación espacial, de manera sistemática, entre propiedad y jurisdicción; en este sentido, ya hemos aludido a la existencia de tierras francas, libres de cualquier pecho o partición, que no pertenecían a las señorías respectivas. Sin embargo, esa misma contraposición entre tierras libres y pechadas habla de la importancia y frecuencia del canon enfitéutico. En efecto, la enfiteusis señorial conoció en los feudos del antiguo reino de Valencia una singular propagación a favor de tres sucesos históricos de primera magnitud, es decir, conquista cristiana, expulsión de los moriscos y la gran etapa roturadora que arranca del último cuarto de siglo XVII y cubre la centuria siguiente. ${ }^{9}$ Con carácter complementario, a la expansión del establiment contribuyeron también la creación de luga-

\footnotetext{
${ }^{8}$ Cavanilles, A. J.: Observaciones sobre la Historia Natural, Geografía, Agricultura, Población y Frutos del Reyno de Valencia. En Madrid, Imprenta Real, 1795. Valencia, Soler, 1972, I, pp. 125-127.

${ }_{9}$ Gil Olcina, A.: Op. cit. 7, pp. 299-303.
} 
res alfonsinos, hecho de raigambre foral y específicamente valenciano, ${ }^{10}$ y el saneamiento de áreas palustres. ${ }^{11}$ En resumidas cuentas, no hay riesgo en afirmar que, a finales del Antiguo Régimen, buena parte de las tierras cultivadas en los señoríos valencianos eran pechadas.

Ya se ha indicado que el establiment señorial combina un elemento solariego, plasmado en el contrato enfitéutico, y otro jurisdiccional; este último no sólo incorpora vasallaje y regalías, sino que incide sobre el primero, reforzando de manera evidente, en detrimento del dominio útil, al mayor y directo, que reviste una condición verdaderamente eminente, con un derecho de comiso muy amplio y firme apoyo en el ejercicio de la jurisdicción. La división de dominios queda así mediatizada por la componente jurisdiccional, con su lesiva secuela de derechos exclusivos, privativos y prohibitivos.

Además de la percepción del canon anual, componentes esenciales de la enfiteusis señorial valenciana son laudemio, fadiga, cabreve y comiso, con íntima y estrecha relación entre sí, tal y como subraya Benlloch en los párrafos anteriormente transcritos.

\section{Laudemio o luísmo (llü̈sme)}

Derecho consustancial e inherente al dominio directo, y obligación del enfiteuta en igual medida, es el laudemio, hasta tal extremo que, tras el extrañamiento de los moriscos, la carta puebla de la Encomienda de Sagra y Cenete, de la Orden de Santiago, precisa que el censo perpetuo impuesto sobre casas y predios «en Castilla se llama emphiteotical y en este Reyno de Valencia fadiga y lluisme» ${ }^{12}$.

Belluga señala que «laudemium est de foro extranea pars rei emphyteoticariae, quae venditur vel alienatur» ${ }^{13}$, definición coincidente con la establecida en el fuero XVIII de la rúbrica «De feudis». Según Monforte, el

${ }^{10}$ Gil Olcina, A.: «Reformismo ilustrado, colonización interior y restablecimiento del fuero alfonsino», Agricultura y Sociedad, 1990, 56, pp. 79-112.

11 Altamira y Crevea, R.: Derecho consuetudinario y economía popular de la provincia de Alicante. Madrid, 1905, pp. 96-127. León Closa, T.: «Aportación al estudio de la colonización de la Vega Baja del Segura», Anales de la Universidad de Murcia, XXI, 196263 , núms. 3 y 4 , pp 95-140.

${ }_{12}$ Carta Puebla de la Encomienda de Sagra y Cenete de la Orden de Santiago, A.R.V., Manaments y Empares, Lib. 5, mano 46, cap. 2, f. 29.

${ }_{13}$ Monforte Báguena, A.: Los contratos acerca de la tierra en Valencia. Valencia, Tip. Moderna, 1922, p. 71. 
laudemio consiste en la cantidad que se satisface al señor directo en el acto de aprobar la enajenación, gravamen o permuta de la finca establecida; así, pues, supone la participación del censualista en el precio de transmisión del dominio útil y posee condición de fruto del dominio directo. La denominación de laudemio (llü̈sme o loysme) acabó por prevalecer sobre las de quincuagesima oforiscapio, sinónimos que, empleados en sentido estricto, indican laudemios de una cuantía determinada, es decir, 1/50 del precio pagado por el dominio útil y 1/3 respectivamente.

En opinión de Castán, ${ }^{14}$ el laudemio es uno de los derechos que más conserva el antiguo sabor señorial de la enfiteusis y que mejor encarna la concepción de dominio dividido. La carta puebla de Bélgida especifica «que de totes les ventes, donacions y transportacions y de qualsevol genero de actes que es faran, hajen de pagar lluisme a dit Senyor a dos sous per lliura, exceptats los que conforme a furs del present Regne no den lluisme», ${ }^{15} \mathrm{y}$ en una concordia, del año 1625, del duque de Gandía con sus vasallos-enfiteutas de Oliva, se hace constar que éstos habrán de satisfacer los laudemios impagados en los actos de venta, partición, permuta, transportaciones y cargamentos de censales. ${ }^{16}$

Es de resaltar que la cuantía del llü̈sme, fijada por el fuero tercero de la rúbrica «De feudis», que es de $1 / 10$ para ventas y permutas y $1 / 20$ en hipotecas, resulta muy superior a la quincuagésima prescrita por el Derecho Romano, Derecho Canónico, Partidas y Novísima Recopilación. Dada su cuantía de 1/10, en las ventas, motivo más frecuente de la percepción de laudemio, éste pasó a denominarse en el Bajo Segura décima. ${ }^{17}$ Hasta ahora en los establiments señoriales valencianos no se han documentado laudemios de importe equivalente al de los foriscapios catalanes, pero sí superior al señalado en los Furs. Es el caso de la carta puebla del condado de Buñol, con motivo de la expulsión de los moriscos, que presenta, además, la particularidad de laudemios con diferentes porcentajes para un mismo acto sobre cosas diferentes; así,

${ }^{14}$ Castán Tobeñas, J.: «Derecho de cosas (Propiedad y derechos reales restringidos)», Derecho Civil Español, Común y Foral. Madrid, Inst. Ed. Reus, 8. ${ }^{\text {a }}$ ed., 1951, t. II, p. 611.

${ }_{15}$ Escritura de establecimiento de la Villa de Bélgida, 1611. A.R.V., Real Justicia, 1739-1741, Lib. 15, cap. XXV, f. 26.

${ }_{16}$ Copia del establecimiento nuevo que otorgó el Excmo. Sr. D. Carlos de Borja y Centelles, duque de Gandía, conde de Oliva, Marqués de Lombay, en 16 de marzo de 1625 a los vecinos de la Villa y arrabal de Oliva. A.R.V., Real Justicia, 1765-1768, Lib. 26, f. 424 y $424 \mathrm{v}$.

17 Gil Olcina, A. y Canales Martínez, G.: Residuos de propiedad señorial en España. Perduración y ocaso en el Bajo Segura. Alicante, Instituto Juan Gil Albert.

$$
-207-
$$


para ventas, el laudemio es $1 / 5$ del valor de casas, tierras de huerta, olivares, eras y corrales de ganado, 1/6 en los cañares y $1 / 7$ para secanos y viñedos. Por su parte, aunque pudiese existir rebaja mediante gracia específica, en la Valldigna, a finales del quinientos, el importe habitual del laudemio, que era de cuatro sueldos por libra, ascendía al doble del habitual; era la quinta parte, y no la décima, del precio del dominio útil. ${ }^{18}$

Con independencia de que en estos casos resulten excepcionales, hecho muy digno de atención es que los Furs fijan unos laudemios muy crecidos, que, en ventas y permutas, quintuplican la quincuagésima. Castán fundamenta este hecho en el carácter híbrido de la enfiteusis senorial en Valencia y Cataluña, ya que el feudo fue en un principio meramente personal, estando absolutamente prohibida su enajenación, de manera que, cuando se debilitó ese rigor, fue natural que se acompañara el permiso de una fuerte retribución. ${ }^{19}$

Tema, a nuestro juicio, innecesariamente controvertido es la significación del laudemio en el conjunto de las rentas señoriales. Covián considera el laudemio como una de las cargas más intolerables; ${ }^{20}$ desde una perspectiva opuesta, ofrece, sin embargo, testimonio en el mismo sentido, al encarecer la importancia de esta percepción, la Noticia circunstanciada del marquesado de Elche... ${ }^{21}$. En contraposición, los ingresos por laudemio resultan irrelevantes en el balance de las rentas señoriales del marquesado de Lombay, si bien, como se ha visto, el gobernador Benlloch se lamentaba de las irregularidades y ocultaciones que reducían la cuantía de este derecho. Sin embargo, parece ocioso encarecer que los ingresos por laudemios quedan ampliamente supeditados a la frecuencia con que se produzcan los actos que lo originan, $\mathrm{y}$, sobre todo, al incremento de valor que pueda experimentar el inmueble establecido.

En cuanto al primer aspecto, hay que recordar la existencia del llamado quindenio, tipo de laudemio instituido para compensar, en este aspecto, la amortización del bien enfiteuticado por corporaciones perpe-

${ }^{18}$ Carta puebla del condado de Buñol, 1611. A.R.V., Real Justicia, 1733-1735, Lib. 13, cap. 10, 15, 16, 19 y 23, ff. 446v-447v. Ciscar Pallarés, E.: La Valldigna, siglos XVI y XVII. Cambio y continuidad en el campo valenciano. Valencia, Dip. de Valencia, 1997, p. 101.

${ }_{19}$ Op. cit., II, p. 638.

${ }^{20}$ Covián, V.: «Enfiteusis», Enciclopedia Jurídica Española, Barcelona, F. Seix, 1910, 2. $^{\mathrm{a}}$ ed., t. XIII, p. 559 .

${ }_{21}$ Noticia circunstanciada del Marquesado de Elche; Baronía de Aspe, Planes y Lugar de Patrax: su gobierno, vecindario, cultivos, pechos, diezmos, censos, etc., 1739. AME, leg. 127-A, núm. 1. 
tuas y manos muertas, que debían satisfacer este derecho cada quince años. En los restantes casos, el análisis de Libros de Laudemios, Giradoras, Libros de Enfiteutas o Tablas de Fadigas permite conocer los intervalos con que se producen, en las diversas coyunturas, los contratos jurídicos sujetos a laudemio.

Innecesario es subrayar la incidencia, a los efectos considerados, del incremento de la superficie cultivada y de la multiplicación de viviendas. En este contexto, que es el del setecientos valenciano, hallarían plena justificación las aseveraciones de la mencionada Noticia circunstanciada del marquesado de Elche... y el alegato de Sala, quien denuncia «... que sucede con frecuencia que un pedazo de tierra que cuando se concedió en enfiteusis sólo valía, por ejemplo, diez pesos, a causa de estar inculto, en montaña y entre peñascos o era marjal cubierto casi de continuo de agua, vale doscientos o más cuando se enajena, debido enteramente este aumento a los sudores del enfiteuta y sus hijos sin la menor influencia ni gasto del dueño directo, que, sin embargo, cobra el luismo de estos pobres e inocentes sudores. Y sucede también con mucha frecuencia que estas tierras se venden dos o más veces en quince o veinte años, con la misma carga de haberse de pagar siempre este derecho. En cuanto a casa, es todavía mayor la enormidad». Así, pues, la importancia económica del laudemio aumenta gracias al valor añadido generado a expensas del nuevo colono; por ello, su producto crecería considerablemente durante el siglo XVIII, con la reducción a cultivo y saneamiento de extensas superficies del reino de Valencia.

$\mathrm{Al}$ igual que otros elementos de la enfiteusis señorial, el laudemio tampoco fue inmune al debilitamiento del señorío mayor y directo originado, sobre todo, por la separación del elemento jurisdiccional, incorporado a la Corona por decreto del 6 de agosto de 1811. La décima tornó a ser quincuagésima con las disposiciones abolicionistas de 3 de mayo de 1823 y 26 de agosto de 1837, para trocar también su condición de componente esencial del establiment por el de disposición accesoria del mismo.

\section{Fadiga}

La fadiga o fádiga es la denominación dada tradicionalmente en Aragón, Cataluña y Valencia a un derecho preferente de adquisición cuya 
consecuencia primordial es la extinción del contrato enfitéutico por la consolidación de ambos dominios. Es de resaltar que el vocablo fadiga adquiere en el Bajo Segura singular vigor y excepcional amplitud semántica, hasta hacerse sinónimo de censo enfitéutico. En efecto, el término aparece en protocolos notariales, contadurías de hipotecas y registros de la propiedad con tres acepciones diferentes, dos compartidas con otras áreas valencianas y una tercera propia. Se conoce por fadiga al derecho de prelación ya descrito, ejercitado en los pequeños señoríos de la comarca con frecuencia muy superior a la de los grandes estados nobiliarios valencianos. Se llama asimismo fadiga, como en algunas otras áreas del reino, a la cantidad entregada al censualista por la concesión de la licencia; con este sentido aparece, por ejemplo, empleada dicha voz en los establecimientos enfitéuticos de las Pías Fundaciones, donde la fadiga importaba seis reales de vellón y la satisfacía el comprador. Por último, peculiaridad de la comarca es el manejo del vocablo como sinónimo de censo enfitéutico; de ahí derivan también los nombres de fadigueros a los enfiteutas y de Tabla de fadigas a los Libros de Enfiteutas..$^{22}$ La referida ampliación del campo semántico de la voz «fadiga» se produce en el siglo xviII y perdura en la centuria siguiente, como atestiguan las menciones en los registros de la propiedad.

Controvertido jurídicamente su ejercicio, y en la práctica negado al enfiteuta, la fadiga fue siempre derecho indiscutido del titular del dominio directo. Monforte ${ }^{23}$ la incluye entre las principales atribuciones del señor directo y el fuero XXIII la establece en los términos siguientes: «Si aquel que haura presa alcuna cosa a cens la voldra vendre, lo senyor daquella cossa la pot retenir per aytant de preu como altre hi donara». Covián ${ }^{24}$ afirma que en el antiguo derecho el dominio útil no ejercía el tanteo, y de idéntica opinión es Castán ${ }^{25}$. Por su parte, el susodicho gobernador del marquesado de Lombay subraya que «...es tan precisa esta dominical licencia, que, sin ella, se puede comisar la cosa raíz enagenada en pena de la inobediencia y rebeldía al dominio mayor, a quien la naturaleza del contrato emphiteutico, atribuye esta determinada acción legal». ${ }^{26}$ Salvo pacto en contrario, el plazo para ejercitar

${ }^{22}$ Gil Olcina y Canales Martínez, Op. cit.

${ }^{23}$ Monforte, Op cit., p. 91.

${ }^{24}$ Covián, Op. cit., p. 569.

${ }^{25}$ Castán, Op. cit., II, pp. 635-642.

${ }^{26}$ Benlloch, Op. cit., p. 117. 
el derecho de fadiga era de treinta días, y comenzaba a contar desde el momento en que el enfiteuta comunicaba al señor directo su intención de vender, hipotecar, adjudicar en pago de deuda o permutar.

Para nada se menciona en las cartas pueblas otorgadas a raíz de la expulsión de los moriscos el retracto, que completa el derecho de prelación, con la ventaja sobre el tanteo de la certidumbre del precio; sin embargo, según Covián, ${ }^{27}$ desde el Fuero Real en Castilla y quizá antes en las provincias forales, se habla de las dos instituciones como independientes; de modo que el dominio directo dispondría de dos vías posibles de adquisición del dominio útil. En opinión de Castán, ${ }^{28}$ no se conocía el retracto enfitéutico. Según Borrell Maciá, ${ }^{29}$ la fadiga es el derecho de tanteo y, en puridad de principios, no comprende, por consiguiente, el retracto; si bien estima que, en la realidad, éste forma virtualmente parte de aquella, de manera que la fadiga equivaldría la retracto en caso de que la enajenación se haga sin licencia del dueño directo. En opinión del mismo tratadista, firma y laudemio son incompatibles con el recurso posterior a la fadiga. Conocemos, sin embargo, pactos en contrario incluidos en el Protocolo de Escrituras Públicas respectantes a la Señoría Directa del Excmo. Sr. Conde de Elda; en ellos, concedida la licencia y fijada la cuantía del laudemio, la fadiga se configura como un derecho de retracto durante treinta días a partir de la fecha de firma; ${ }^{30}$ añadamos que, en la enfiteusis señorial valenciana, la acción atribuida al titular del dominio directo en la enajenación sin licencia es el comiso, no el retracto.

Cuestión del máximo interés es la de precisar cuándo la fadiga comienza a ser efectivamente ejercitada por los enfiteutas. A este respecto, en 1770, Carlos III dispuso: "Se declara que no sólo al dueño directo compete el derecho de tanteo dentro de dos meses desde que se le requiere por el útil, sino que también á éste, en calidad de comunero, pertenece expresamente igual derecho cuando el dueño venda su directo dominio, estando igualmente obligado a requerir al útil para que dentro de dos meses use, si quiere, de este derecho» (Ley 112, Tít. XV, Lib. X de la Novísima Recopilación).

\footnotetext{
27 Covián, Op. cit., p. 569.

28 Castán, Op. cit., II, p. 642.

29 Borrell Maciá, A.: «Fadiga», Nueva Enciclopedia Jurídica, 1958, IX, pp. 450-454.

30 «Venta Josef i Diego Olcina a Joaquin Beltran de Josef. Elda i Abril, 27 de 1806», Protocolo de Escrituras públicas respectantes a la Señoría Directa de mi Exmo. Sr. Conde de Elda, autorizados por Josef Amat y Rico Escribano Real y Patrimonial de la misma y su Condado que principia en el Corriente Año 1806. A. M. de Elda.
} 


\section{Derecho de cabrevación}

Afirma Covián que «la costumbre introdujo en Cataluña que los señores de castillos y lugares, al tiempo de cada sucesión, se hicieran reconocer y confesar el dominio con todos los censos, prestaciones y servidumbres, y prometer su pago y cumplimiento, mediante juramento; lo cual, porque se apuntaba en un breve resumen de la historia de las fincas y sus cargas y pertenencia, hasta encontrar el título primordial de adquisición, se llamaba caput breve, y en catalán cap breu, nombre que también llevaba el libro en que se hacía constar el reconocimiento». ${ }^{31}$ El dueño directo estaba facultado para exigir el cabreve o reconocimiento por el enfiteuta del mencionado dominio, haciéndose constar en libros o cabreves (capbreus), además de los datos personales del censatario, los que se tenían por necesarios para la identificación, sin error ni equívoco, de los bienes inmuebles cuyo dominio útil poseía, indicándose, junto a su localización, superficie y linderos, así como los títulos de pertenencia y, por supuesto, el canon, laudemio y fadiga a que estaban tenidos, con el oportuno reconocimiento del dominio mayor y directo. A falta de registros públicos, el cabreve salvaguardaba el dominio directo y aseguraba la percepción del canon y laudemio, al controlar la titularidad del dominio útil.

Destaquemos asimismo que, fuera de algún caso singular, el establiment señorial era perpetuo e irredimible. Entre el centenar largo de cartas pueblas exhumadas de los siglos xvI y xvIII en el antiguo reino de Valencia, sólo la otorgada para el marquesado de Elche a raíz de la expulsión de los moriscos impone censos redimibles; ${ }^{32} \mathrm{y}$, a pesar de ello, la división de dominios perduraba en la práctica totalidad de los expresados establecimientos cuando se decretó la incorporación de jurisdicciones. Todo ello hacía aun más necesaria la cabrevación, ya que, como señala Peset, ${ }^{33}$ un contrato perpetuo corre el riesgo de extinguirse o ver alterado su contenido si no se encuentra estrictamente registrado, y para ello se requería su seguimiento a través de la cabrevación, reflejada en el libro o cabreve con las debidas garantías legales. En el

${ }^{31}$ Covián, Op. cit., p. 703

${ }^{32}$ Gil Olcina, A.: «Las escrituras de establecimiento y venta a carta de gracia de las haciendas de moriscos en el marquesado de Elche», Cuadernos de Geografía, Valencia, 1979, núm. 24, pp. 27-38.

${ }^{33}$ Peset, Op. cit., p. 113. 
acto de la cabrevación el enfiteuta había de probar la legitimidad de sus títulos o, en defecto de ellos, acreditar que venía satisfaciendo el canon por tiempo mínimo de cuarenta años; en este último supuesto, podía el enfiteuta, tras jurar el extravío del título primitivo, exigir el otorgamiento de la carta precaria o título precario denominado Acte en defecte Actes, en la que el señor directo rubricaba el apeo de la finca censida y la pensión anua.

A expensas suyas, el titular del dominio directo podría citar a cabrevar siempre que lo deseara; en cambio, a costa del enfiteuta, sólo cada diez años, tal y como señalaba el fuero CCV de las Cortes de 1645. De conformidad con el mismo, el capítulo 26 de la concordia de Molins disponía, en 1697, que «es cabreu de deu en deu anys. Ittem ab pacte y condicio que los dits pobladors y vasalls y sos succesors tinguem obligacio de cabrevar y regoneixer la señoria directa de deu en deu anys y sempre que els sitara davant del jutge que per a este efeccte nomeran los dit señor y sos succesors, y deixamdho de fer presehint la interpelacio disposta per dret incurreixquen en comis les terres y casses ab totes les millores...». ${ }^{34}$ Sin embargo, tras la derogación de Furs por real decreto de 29 de junio de 1707, no faltó escritura pública autorizada años después que acortase el periodo de cabrevación obligatoria al lustro; así sucedió con el Colegio de Predicadores (Santo Domingo) de Orihuela, que, muy interesado en controlar los rompimientos de tierras en los Hondones (actual Hondón de los Frailes), hizo constar en la escritura de suplimiento de títulos, otorgada en 1725, que «los dhos enphiteutas y sus succesores esten obligados a cabrevar dichas tierras y casas de sinco en sinco años y reconoser por Señor Directo de aquellas à dicho Colegio Retor y Colegiales que oy son i por tiempo fueren de el pena de comiso». ${ }^{35}$ No fue ésta, empero, norma general. Al contrario, la práctica se relajó y distanció en el tiempo; dicha dejadez fue pródiga en consecuencias, ya que, en determinadas circunstancias o por distintas causas, permitió la transformación más o menos subrepticia, y parece que considerable, de tierras y casas pechadas en francas. A la larga, esta carencia de cabreves actualizados repercutiría de manera muy negativa en la inscripción registral del dominio directo, con numerosas denegaciones.

${ }^{34}$ Bernabé Gil, D.: Tierra y Sociedad en el Bajo Segura (1700-1750). Alicante, Univ. de Alicante-Caja de Ahorros Provincial, 1982, pp. 212-213.

${ }_{35}$ Bernabé Gil, Op. cit. 34 , p. 229. 
La cabrevación contaba con procedimientos y actuaciones judiciales. Bas y Galceran, en su Theatrum Iurisprudentiae, se refiere a ello en los términos siguientes: «La Práctica de citar à cabrevar, y pagar censos en el present Reyno se reduce à que el Señor directo, ó su Procurador haze instancia ante el Juez delegado para que se cite a cabrevar para el dia subsiguiente al emphiteuta para T. hora, y para la casa del Juez delegado, y si el emphiteuta vive en la misma Ciudad, Villa ò Lugar en donde se haze la citacion, no es necessario despachar cedula firmada del delegado para la citacion, sino es que el portero verbalmente haga la citacion, bien es verdad que se puede en este caso tambien despachar cedula firmada, que vulgarmente dezimos Albaranets, pero si el emphiteuta viviere fuera el Lugar, Villa ò Ciudad, se acostumbran a despachar dichas cedulas firmadas... Acostumbranse hazer tres citaciones con estas cedulas... No compareciendo el emphiteuta à esta primera citacion, se le acusa la contumacia, y se despacha segunda citacion... Intimado este segundo precepto, si no compareciese el emphiteuta a la hora señalada, se le acusa la contumacia, y se provee que se despache tercera citacion sub poena commissi, y en este caso debe continuar el Escrivano la acusacion de la contumacia, como tambien en todos los demas, pero con especialidad la contumacia de esta segunda citacion debe continuarse en esta forma:

Die XV. Maij MDCLXXXVIII. Lo M.F.T. Dotor en drets, Iutge delegat en totes les causes emphiteuticals de S.T. instant, y requirent lo dit F. T. pulsata hora undecima, ante meridiem, admissa contumacia contra S. T. del segon manamente de que vinga à cabrevar y pagar censos Providet, quod siat tertia citatio sub poena commisi pera demà de 10 à 11 hores del mati à la casa del dit Iutge delegat, que la te en T. Parroquia en lo carrer de T. à cabrevar, y pagar censos. Recepit $F$. T. Notarius et Scriba.

En execucion de esta Provision, se despacha la tercera citacion à cabrevar sub poena commissi, intimandola, ó sin cedula en los casos ya notados, ò con cedulas quando es preciso, despachandola en esta forma:

Demanament, y provisiò del M.F.T. Iutge delegat en totes les causes emphiteuticals de S.T. instant, y requirent lo dit S.T. intiman, notifican, y manan a F.T. que vinga à cabrevar, y pagar censos per tercera citació segons furs, ab pena de commis, pera demà de 10 à 11 hores del mati, à la casa del dit M. Iutge delegat, que la te en T. Pa-

$$
-214-
$$


rroquia en lo carrer de $T .{ }^{36}$ Para la cabrevación no se podía obligar al enfiteuta a un recorrido de ida y vuelta que supusiera más de un día de camino; en el reino de Valencia, como máximo tres leguas de distancia, por entenderse que podían hacerse desde el alba al mediodía, quedando la tarde para el retorno.

El propio Bas y Galcerán contempla el supuesto de que la citación a cabrevar no fuese procedente, de manera que «si el citado a cabrevar no posseyere cosa censida al que le cita, ò si entendiesse que no puede provar su dominio al Señor directo, recurre a la Real Audiencia, ò à la Corte de la Governacion de las citaciones a cabrevar [...], y inhibiendose el Juez delegado, se conoce, y decide en el Tribunal Real si el Senor directo tiene una señoría directa en predio alguno de los que possehe el citado [...] Si el emphiteuta no quisiese recurrir de las citaciones à cabrevar, à la Governacion, ó al Real Consejo, sino es que quissiese que el Iusticia, y Iuez Ordinario, conociesse, y determinasse, si possehe bienes censidos, ó subiugados, no se debe recurrir de las citaciones a cabrevar [...] sino es que se podrá proponer instancia ante el Iusticia, en que se pida se declare, que el emphiteuta no puede ser citado, ni convenido ante el Juez delegado, por no tener bienes algunos sugetos al dominio directo de aquel Señor...» Tampoco el comiso era automático si no se acudía a la tercera de las citaciones, ya que el enfiteuta podía «purgar la mora antes de contestar la lid, pagando los censos, y pidiendo que sea admitido a cabrevar. Esto se practica hazer proponiendo el emphiteuta, luego que le ayan notificado la instancia de commisso, un libello ante el juez delegado». ${ }^{37}$

Innecesario es insistir en que los cabreves resultan más detallados en unos casos que otros, y difiere asimismo su frecuencia según señoríos y épocas. Antes hemos aludido a la cláusula en la que el Colegio de Predicadores de Orihuela acortaba, abolidos los Furs, el periodo obligatorio de cabrevación en cinco años, revelando así un interés por este derecho que fue habitual en los titulares de abadengos y señoríos eclesiásticos, que muestran no sólo las frecuencias más altas de cabrevación, sin que falte alguna excepción, sino los cabreves más precisos y detallados. Ejemplos prototípicos ofrecen de ello, en el Bajo Segura, el Colegio de Predicadores, que rigió la Universidad de Orihuela, y el cabildo cate-

${ }^{36}$ Baset Galceran, N.: Theatrum Iurisprudentiae Forensis Valentinae. Valencia, ex Typ. Laurentii Mesnier, 1690. Pars I. Cap. XXX, «De iuribus domini directi», p. 543.

37 Baset Galceran, Op. cit., p. 560. 
dralicio de esta ciudad, que poseían, respectivamente, los señoríos alfonsinos de Redován y Bigastro; ${ }^{38} \mathbf{o}$, en Valencia, el Colegio del Corpus Christi, fundación del Patriarca Ribera, al que correspondían los de Burjasot y Alfara. Concernientes al primero de estos dos, poco o nada tiene que envidiar a un asiento registral el fragmento de un cabreve que transcribe Peset, redactado en los términos siguientes: «...medio juramento, dix e respost que deté e posseheix nou fanegades de terra garroferal, situades e posades en lo terme de Burjasot, partida dita de la Coma, tengudes sots directa señoria del dit collegi de Corpus Christi, señor del dit lloch de Burjasot, a cens de cinch sous y güit [=vuit] diners, pagador a San Joan de Juny en una paga, ab dret de fadiga $y$ luisme y tot altre plen dret emphiteòtic segons Fur de València...la qual tené lo quondan Luis Navasquillo, pare de ell, confessant compra de Catherina Barberà y de Ricla y altres, ab acte rebut per Jaume Martí Vaciero quondam notari en quince de nohembre de mil cinchcents setanta y cinch, ab firma del señor directe rebudo per lo dit notari en catorce de juliol de mil cinchcents setanta nou; lo qual dit Luis $\mathrm{Na-}$ vasquillo ab son ultim testament rebut por Francés Joan Ortiz, quondam notari en vint y quatre de mars cinchcents güitanta [=vuitanta] y hu, y publicat a tranta hu dels dit mes e any, feu e instituhi hereu seu al dit Vicent Navasquillo...» ${ }^{39}$.

En este mismo orden de cosas, el 21 de enero de 1564, el abad del monasterio cisterciense de la Valldigna ordenaba que todas las transmisiones de dominio útil y demás causantes de laudemio en dicho señorío se realizasen ante el fedatario del mismo, así como que los referidos actos fuesen declarados, en el plazo perentorio de tres días, para satisfacer el citado derecho, objeto de registro en un libro especial. Benítez Sánchez-Blanco ${ }^{40}$ ha analizado el primero de estos libros de laudemios, que contiene los datos siguientes: fecha, notario y, en su caso, circunstancias especiales de la transmisión u operación que generaba el laudemio; identidad pormenorizada de quienes la efectuaban; $y$, por último, noticia detallada de las características físicas y situación legal del

${ }^{38}$ Gil Olcina y Canales Martínez, Op. cit., pp. 95-120. Canales Martínez, G. y Martínez García, I.: El señorío eclesiástico de Bigastro (siglos XVIII-XIX). Alicante, Instituto «Juan Gil-Albert», 1994.

${ }^{39}$ Peset, Op. cit., p. 114.

${ }^{40}$ Benítez Sánchez-Blanco, R.: «Compraventa de bienes enfitéuticos en Valldigna (Valencia), 1564-1569», Actas IV Simposio Internacional de Mudejarismo: Economía, 1987. Teruel, Instituto de Estudios Turolenses, 1992, pp. 293-306. 
inmueble correspondiente. Innecesario resulta encarecer que estos libros son fuente del mayor interés para el estudio de la propiedad agraria, ya que, si bien carecen de la condición global y sintética del cabreve para un momento dado, proporciona una información muy útil sobre la valoración de las tierras y sus diversos cultivos. $\mathrm{Y}$ otro tanto sucede con el llamado Libre de Magram para las aljamas, generalmente escrito en algarabía y a veces traducido a aljamía, y con los Llibres de cappatro; unos y otros cumplen función similar a las Giradoras, es decir, libros de anotaciones concernientes a la titularidad del dominio útil y a sus obligaciones con el directo, cuya finalidad era la de mantener actualizados los datos. Sin embargo, todos ellos carecían de la fuerza legal y probatoria del cabreve, al que, en ocasiones, los enfiteutas se resistían. De las dificultades con que tropezó el monasterio de la Valldigna para cabrevar en la segunda mitad del siglo XVI da cumplida e interesante noticia Ciscar Pallarés en la obra citada.

Otro ejemplo de este tipo de comportamiento constituye la minuciosa concordia de Bigastro, ${ }^{41}$ con cuarenta y dos capítulos, otorgada el 10 de octubre de 1701 y ratificada, con ciertas modificaciones, el 2 de junio de 1715, adoptaba una serie de cautelas para preservar el dominio directo. En efecto, el Cabildo no sólo impuso a sus enfiteutas la obligatoriedad de otorgar todas las escrituras concernientes al dominio útil ante un escribano determinado, al objeto de concentrar toda la información en protocolos sucesivos, sino que llevó libro registro de dichos actos, y dispuso, además, en el intervalo de 1715 a 1825 la ejecución de seis cabreves. ${ }^{42}$ Asimilable en gran medida al comportamiento de esta clerecía culta ${ }^{43}$ fue el de un buen número de los nobles titulares de señoríos alfonsinos, caballeros y generosos, de comportamiento burgués, con actitudes precapitalistas, impregnadas de una considerable dosis de racionalismo económico y capaces de conciliar y apoyar sus arraigados designios de promoción nobiliaria con una cuidada administración de sus patrimonios y, en determinados casos, perspicaz política de inversiones. Excusado es encarecer que, con estos planteamientos, no descuidaban las cabrevaciones. Circunstancia esta última

41 Canales Martínez y Martínez García, Op. cit., pp. 259-272.

${ }^{42}$ Canales Martínez y Martínez García, Op. cit., pp. 77-119.

${ }^{43}$ Andrés Robres, F.: Actitudes económicas de la clerecía culta en el Antiguo Régimen. Política financiera del Real Colegio del Corpus Christi de Valencia. Valencia, F. Domenech, S.A., 1986. 
que, por el contrario, no es infrecuente entre los Grandes, titulares de múltiples vinculaciones e infinidad de señoríos, donde la cabrevación se limita a cumplir su finalidad básica, desprovista de la redacción minuciosa y primorosa con que muestra habitualmente, en los casos anteriores.

Como ejemplo de esta otra forma de proceder recogemos la fórmula impresa y los párrafos iniciales de un caso concreto pertenecientes a la cabrevación practicada, el año 1674, en el marquesado de Elche. Es de notar que, concebida la susodicha fórmula con validez general para otros dominios del titular del marquesado, vinculado éste a una de las primeras casas de la nobleza española, aparecen en aquélla diversos espacios en blanco, tal y como figuran en la transcripción siguiente: «Sepan quantos la presente escritura vieren, como en la Villa de.

al presente asiste.............Iuez emphiteutical nombrado por el excelentísimo Señor Duque Duque de Arcos, Aveiro y Maqueda Marqués de Elche etc. Con nombramiento dado por Secretaria en la Villa de Madrid, en........ mes de...........Año de..........firmado de mano de dicho Excelentísimo Señor, sellado, y refrendado por..............Secretario de su Excelencia, pareció en................del mes de.................Año corriente............Procurador Fiscal Patrimonial de dicho Excelentísimo Señor, y dixo que para los presentes dia, y hora tenia citado, y convenido a.............. para que mediante juramento diga, y declare, que bienes tiene, y posee sujetos a censo, partición de frutos, y otro qualesquier drecho emphyteutico y Señoria directa de dicho Excelentísimo Señor, y succesores de su Excelencia, y con quales titulos. Por lo qual requeria a dicho Iuez le mandara hazer dixho juramento para el efeto referido; y su merced lo defiriò y mando hazer, y aviendo jurado dicho....................sobre la señal de la Cruz, en mano, y poder de su merced confessò, y declarò, que possehia los bienes siguientes:

Reconose poseher un pedazo de tierra blanca en el llano que alinda de levante con un camino de Catral de poniente tramontana y mediodia con tierras de la $V^{a}{ }^{a}$ de Luis Ripoll que seran 5 th.

Item otra blanca de tierra medianos riego de Catral que alinda de levante con olivar de Miguel Torres de poniente con olivar de Miguel Molina de mediodia con olivar de To-

$$
-218-
$$


mas Ripoll y de tramontana con medianos de dho. Torres... ${ }^{44}$

Como se ha dicho, la enfiteusis fue, con pocas salvedades, la forma jurídica de explotación habitual de la propiedad agraria señorial; y, por ello, el cabreve proporciona, casi siempre, un conocimiento detallado de aquélla y, en los casos menos detallados, una aproximación significativa y válida. Dicha fuente reviste asimismo interés para el estudio de los establiments correspondientes, en al ámbito valenciano, al Real Patrimonio, y en especial para documentar rompimientos de tierras realengas. De 1527 data una Breu instrucció del Mestre Racional de la ciutat y Regne de Valencia, pera els cabreus que sa magestat ha manat que los Batles de les ciutats, viles y llochs de dit regne fassen de deu en deu anys cascú en lo districte de la sua Batlía conforme al orde que dit Mestre Racional los manará; el procedimiento contenido en la misma coincide sustancialmente con el ya expuesto, incorporando las peculiaridades derivadas de la pertenencia de los inmuebles censidos al Real Patrimonio. ${ }^{45}$ Por desgracia, tras la abolición de fueros, sólo en contadas ocasiones el Intendente General ordenó cabrevaciones de bailías. Ejemplo prototípico constituye el cabreve practicado, durante el período 1781-86, en la Gobernación de Alicante, con la finalidad de poner orden en la caótica situación en que se hallaba dicha masa de bienes censidos, que incluía no sólo tierras, casas, hornos y molinos sino determinados derechos, como los de peso medida o tiraje y barcaje del puerto. ${ }^{46}$

Para remediar abusos de todo tipo, hacer frente a las usurpaciones, clarificar las regalías y reclamar los impagos no prescritos de pensiones enfitéuticas, luismos y quindenios, el Procurador Patrimonial recomendó «...la formación de un cabreve general que jamás se ha hecho ni podido conseguir de aquella Bailía, estableciendo al mismo tiempo en ella la ritualidad de las escrituras del cabreve, establecimientos, licencias y demás según la práctica y estilo [...] en confor-

${ }^{44}$ Cabreve de las 4 Alquerías. 2. ${ }^{\circ}$ Año 1674, N. ${ }^{\circ}$ 665, pp. 98-98. Procedente del Archivo Particular de don Juan Gómez Brufall. Elche. AME:

45 Alberola Romá, A.: «Aportación al estudio de la enfiteusis en tierras realengas. Comentario a unas instrucciones de cabrevación». En La propiedad de la tierra en España. Alicante, Dpto. de Geografía, Universidad de Alicante, 1981, pp. 141-152.

${ }^{46}$ Alberola Romá, A.: Jurisdicción y propiedad de la tierra en Alicante (ss. XVII y XVIII), Alicante Ayuntamiento-Universidad, 1984, pp. 367-369. 
midad de la Instrucción mandada observar por S.M...». ${ }^{47}$ En noviembre de 1780 el Intendente General del Reino de Valencia, a propuesta del Asesor del Real Patrimonio, designó al Juez Subdelegado «...para el cabreve de la ciudad de Alicante, con una recopilación de todos los bienes, regalías y piezas enfitéuticas que se corresponden al Real Patrimonio, con individual justificación que acrediten su permanencia...». ${ }^{48}$ Objetivos básicos del cabreve eran precisar las regalías que el Real Patrimonio tenía censidas a la ciudad de Alicante, el cobro de atrasos en los censos enfitéuticos y la subsanación de usurpaciones. Ocioso resulta encarecer la conflictividad del primer cometido, con alegatos encontrados; la ciudad fue incluida en el Libro de Condena de los Enfiteutas, al igual que los restantes censatarios que el Juez Subdelegado consideró deudores por algún concepto. Por su parte, quienes ocupaban, sin establecimiento alguno, tierras realengas, hubieron de pagar un real de vellón por jornal y solicitar el oportuno suplimiento de títulos. De la importancia y amplitud de la cabrevación hablan las cifras siguientes:

RESUMEN GENERAL DEL CABREVE DE LA BAILÍA DE ALICANTE (1781-86)

\begin{tabular}{|c|c|c|c|}
\hline Inmuebles censidos & $\begin{array}{l}\text { Número } \\
\text { de fincas }\end{array}$ & Enfiteutas & Rentas anuales \\
\hline Tierras . & 789 & 705 & 287 L. 14 s. 9 d. \\
\hline 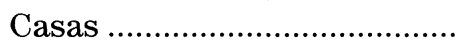 & 256 & 191 & 19 L. 13 s. 9 d. \\
\hline 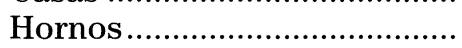 & 56 & 59 & 28 L. 11 s. 6 d. \\
\hline 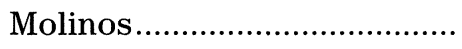 & 14 & 16 & 6 L. 18 s. 6 d. \\
\hline 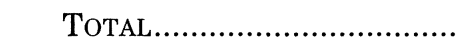 & 1.115 & 971 & 342 L. 18 s. 6 d. ${ }^{49}$ \\
\hline
\end{tabular}

Añadidas a dificultades administrativas, las averiguaciones encaminadas a corregir las perniciosas secuelas de una prolongada etapa de abandono, desorden y abusos de todo tipo motivaron que la cabrevación durase más de un lustro, cuando una normal concluía en meses o, todo lo más, en un año.

47 Alberola Romá, A.: Op. cit., 46, p. 364.

48 Alberola Romá, A.: Op. cit., 46, p. 369.

49 Alberola Romá, A.: Op. cit., 46, p. 386. 
Entre otros, han manejado cabreves para reconstruir la estructura del dominio útil y seguir su evolución, en sus respectivos ámbitos de estudio, A. Alberola Romá (Jurisdicción y propiedad de la tierra en Alicante. Ss. XVII y XVIII, 1984), E. Ciscar Pallarés (La Valldigna, siglos XVI y XVII. Cambio y continuidad en el campo valenciano, Valencia, 1997), C. Domingo Monerris (La Plana de Castellón. Formación de un paisaje agrario mediterráneo, Castellón, 1983), A. Gil Olcina y G. Canales Martínez (Residuos de propiedad señorial en España. Perduración y ocaso en el Bajo Segura, Alicante, 1988), E. Gozálbez Esteve (Análisis de un señorío valenciano. El marquesado de Lombay, 1990), A. Grau Escrihuela (Señorío y propiedad en los Dominios Valencianos de la Casa de Medinaceli. El ducado de Segorbe entre los siglos XVI y XVIII, Alicante, 1996), A. Mora Cañada (Monjes y campesinos. El señorío de la Valldigna en los siglos XVI y XVIII, Alicante, 1986) y J. Romero González (Propiedad agraria y sociedad rural en la España mediterránea. Los casos valenciano y castellano en los siglos XIX y XX, Madrid, 1983).

\section{Giradoras o Libros de enfiteutas}

Como se ha indicado, en la época foral el plazo mínimo para cabrevar a expensas del enfiteuta eran diez años, casi siempre excedido en la práctica. Durante ese intervalo, obviamente, se producían transmisiones de dominio útil, por permuta y, sobre todo, venta. El control de dichas operaciones resultaba posible gracias a la obligación en que se hallaba el censatario, bajo pena de comiso, de solicitar la licencia del señor directo para que éste pudiese ejercitar, en su caso, el derecho de fadiga. Conocida así la transmisión del dominio útil, era recogida en las Giradoras, cuyas denominaciones en la comarca del Bajo Segura eran las de Libros de enfiteutas o Tablas de fadigas, continuamente actualizados, como instrumento de seguimiento del dominio útil y salvaguarda del directo, respaldado por las escrituras públicas correspondientes, conservadas en determinados, y a veces obligados, protocolos notariales.

En esencia, una Giradora consistía en un libro que incluía, por orden alfabético, a los enfiteutas con la relación de sus bienes censidos; de ahí la sinonimia con Libros de enfiteutas o Tablas de fadigas. Así, pues, la Giradora, en cuanto a tierras, proporciona datos, pero no siempre completos, de localización, superficie, cultivo y pensión enfitéutica. 
Por vía de ejemplo, transcribimos parte de la hoja o ficha de un enfiteuta, tal y como aparece en la Giradora del condado de Elda de 1624:

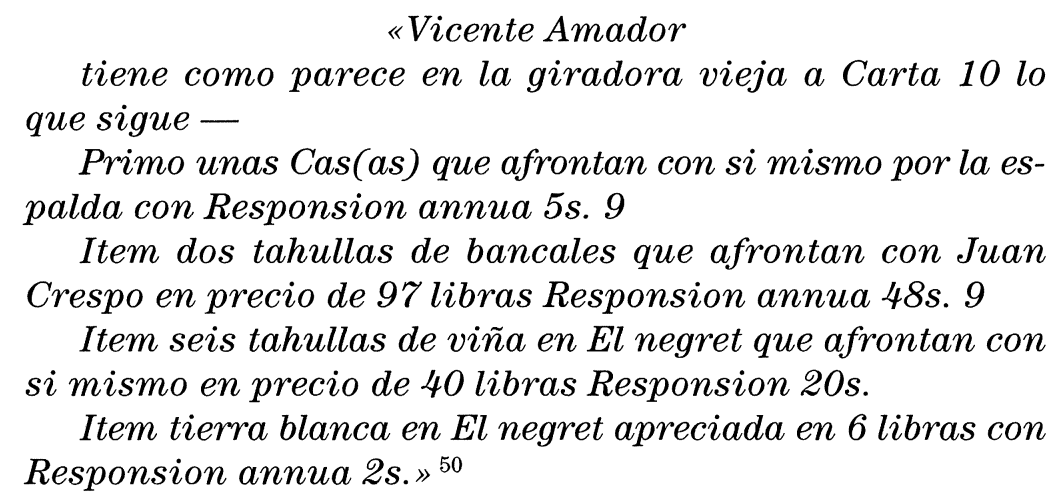

Primo unas Cas(as) que afrontan con si mismo por la espalda con Responsion annua 5s. 9

Item dos tahullas de bancales que afrontan con Juan Crespo en precio de 97 libras Responsion annua 48 s. 9

Item seis tahullas de viña en El negret que afrontan con si mismo en precio de 40 libras Responsion 20 s.

Item tierra blanca en El negret apreciada en 6 libras con Responsion annua $2 s . » 50$

Es de notar que en el condado de Elda no existía partición de frutos, reducido el canon enfitéutico a pechos; a mucha distancia de éstos, diezmos y regalías proporcionaban la mayor parte de los ingresos señoriales. Como se ha indicado, en las Giradoras, Llibres de bens y Capatrós de bens figuran los enfiteutas por orden alfabético de apellidos con los sumarios respectivos de bienes censidos, que detallan el valor estimado de establecimiento, responsion anua y, a veces, superficie de las parcelas y cultivo. Una de las más completas series de Giradoras se conserva en los archivos municipales de Elda y Petrel. ${ }^{51}$ Notoriamente más detallados resultan las Tablas de las fadigas de Redován y los Libros de enfiteutas de Bigastro, señoríos alfonsinos correspondientes al Colegio de Predicadores de Orihuela y al Cabildo catedralicio de esa ciudad respectivamente.

\section{Algunas conclusiones}

Para remediar «estelionatos, pleytos y perjuicios a los compradores, é interesados en los bienes hipotecados, por la ocultación y obscuridad de sus cargas», la Real Pragmática de 31 de enero de 1768 instituyó

\footnotetext{
${ }^{50}$ Giradora de 1624 (al cierre puede situarse en 1630). Agradezco profundamente a doña Consuelo Poveda Poveda que me facilitase el acceso a esta documentación.

${ }^{51}$ Belando Carbonell, R.: Realengo y señorío en el Alto y Medio Vinalopó. Alicante, Universidad de Alicante, 1990, p. 110.
} 
los Oficios de Hipotecas. Se trataba, como hace notar Roca Sastre, ${ }^{52}$ de un embrión de moderno Registro de la Propiedad. Además, el sistema ganó mucho en eficacia con la implantación en 1829, del impuesto de hipotecas, sucesor de la alcabala y precedente próximo de los derechos reales.

Tres lustros después, al amparo del Real Decreto de 23 de mayo de 1845 que reformaba el citado impuesto de hipotecas, nacieron las Contadurías de Hipotecas. Diez años más tarde, el Real Decreto de 8 de agosto de 1855 formalizaba un estado de opinión generalizado sobre la urgente necesidad de reformar y completar el sistema registral; ${ }^{53}$ al mandato contenido en esta norma vino a dar respuesta la innovadora Ley Hipotecaria de 8 de febrero de 1861, que, junto con su Reglamento, entró en vigor el 1 de enero de 1863.

Muy en síntesis, este es el proceso que condujo a la creación y perfeccionamiento de registros públicos, pero con anterioridad esa función fue asumida, en cierto modo, para los bienes establecidos en el antiguo reino de Valencia, particularmente abundantes en los dominios señoriales, por los cabreves. De ahí que, con el complemento de Libros de laudemios, Giradoras o Libros de enfiteutas y protocolos notariales, constituyan una fuente de singular interés y valor para el conocimiento de las estructuras del dominio útil y evolución de cultivos en el Antiguo Régimen.

Resumen: Control del dominio útil y salvaguarda del directo en la enfiteusis senorial valenciana: los cabreves. A finales del Antiguo Régimen los señoríos cubrían las tres cuartas partes del territorio entonces valenciano. El elemento solariego quedaba, en extensión, a la zaga del jurisdiccional, y aun más distante el total de tierras establecidas, ya que existía en aquéllos la distinción básica entre francas y pechadas. Sin embargo, esa misma contraposición habla de la importancia y alta frecuencia del censo enfitéutico, forma jurídica de explotación ampliamente dominante en el labrantío valenciano señorial.

Fuera de algún caso singular, el establiment señorial era perpetuo e irredimible, con grave riesgo de daño o, incluso, extinción, si las transmisiones del dominio útil no eran objeto de control y seguimiento mediante la cabrevación, acto de reconocimiento formal por el enfiteuta de la sujeción al dominio directo de los bienes censidos, detalladamente descritos para prevenir falseamientos u ocultaciones. De ahí el extraordinario interés de los libros resultantes, o cabreves, para el estudio de la propiedad agraria en dicha época.

${ }^{52}$ Roca Sastre, R. M. y Roca-Sastre Muncunil, L.: Derecho Hipotecario, 7. ${ }^{\mathrm{a}}$ ed., Barcelona, 1979, p. 110

${ }_{53}$ Roca Sastre, R. M. y Roca-Sastre Muncunil, Op. cit., p. 116. 
PALABRAS CLAVE: Geografía histórica. Fuentes precatastrales. Valencia. Cabreves.

RÉSUMÉ: Le contrôle du «dominio útil» et la sauvegarde du «dominio directo» en la enfiteusis valencianne: les cabreves. A la fin de l'Ancien Régime, les domaines seigneuriaux recouvraient les trois quarts du territoire alors valencien. L'élément noble restait, en étendue, en arriere des terres juridictionnelles, et encore plus au-delà total des terres établies puisqu'il existait déjà dans celles-ci la distinction basique entre franco et emprunts. Cependant ce même contraste met en relief l'importance et la haute Fréquence de l'emphytéose, une forme juridique d'exploitation très dominante dans le terrain cultivable valencien de la seigneurie.

En dehors de cas particuliers, l'établissement seigneurial étail perpétuel et irrachetable, avec un grand risque de dommages ou même l'extinction, si la transmission du domaine utile n'était pas objet de contôle et de suivi au travers de la «cabrevación», un acte de reconnaissance formel par l'emphytéote de la possession directe des biens recensés, décrits de manière très détaillée pour prévenir des faux ou des dissimulations. De là l'extraordinaire intérêt des livres se rapportant à ce thème ou «cabreves» pour l'étude de la propriété agraire pendant cette période.

Mots CLÉs: Geographie historique. Sources precadastrales. Valencia. Cabreves.

ABSTRACT: Control of the useful property and safe of the direct property in the Valencian noble enfiteusis: the cabreves. At the end of the ancient régime, «feuda» arcas composed three fourths of the Valencian territory. The ancestral element was, in its extent, bechind the jurisdictional element, and still further behind the whole of the established territory, since there was a distinction between tax-free and texed territory. However, this distinction refers to rhe importance and high frequency of the emphytcusical census, a legal of exploitation which was common in the Valencian arable properties.

Except in particular cases, the domain institution was in perpetuily and irredeemable, with serious risks of loss even, extinction, if transfers of ownership were not controlled and monitored through cabrevación. This term refers to a formal act of emphyteuticary acknowledgment by which the assests in the census were directly subject to the property. These assests were described in detail in order to prevent false claims and concealments. That is why the resulting books are so interesting for the study of agrarian property of that time.

KEY wORDS: Historical Geography. Precatastral Sources. Valencia. Cabreves. 